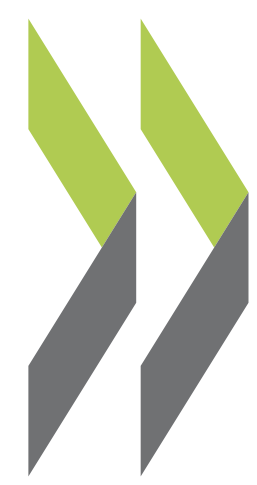

OECD Working Papers on Insurance and Private Pensions No. 20

\title{
Pension Fund Performance
}

\section{Pablo Antolín}




\section{\ęC}

PENSION FUND PERFORMANCE

Pablo Antolin

August 2008

\section{OECD WORKING PAPER ON INSURANCE AND PRIVATE PENSIONS}

No. 20

Financial Affairs Division, Directorate for Financial and Enterprise Affairs

Organisation for Economic Co-operation and Development

2 Rue André Pascal, Paris 75116, France

www.oecd.org/daf/fin/wp 


\begin{abstract}
RÉSUMÉ

\section{Pension Fund Performance}

This report provides an analysis of aggregate investment performance by country on a risk adjusted basis using relatively standard investment performance measures. The report also describes privately managed pension funds around the world and the regulatory environment they face. It compares pension funds across countries according to total assets under management and asset allocation, and briefly discusses certain issues surrounding the data reported by pension funds and regulators on investment returns.
\end{abstract}

JEL codes: G11, G23, C80

Keywords: Investment performance, pension funds, returns on investment, asset allocation, Sharpe ratio, Markowitz mean-variance portfolio maximization.

$$
\text { ****** }
$$

\title{
La Performance des Fonds de Pensions
}

Ce rapport fournit une analyse par pays des performances d'investissement ajustées en fonction du risque et en utilisant des mesures de performance standards. Le rapport décrit également les fonds de pensions privées dans le monde et les régulations auxquels les fonds doivent satisfaire. Il compare les fonds de pension par pays selon leurs actifs totaux et l'allocation de ceux-ci, et examine brièvement les problèmes avec les données rapportées par les fonds de pension et les régulateurs concernant le rendement des investissements.

JEL codes: $G 11, G 23, C 80$

Mots clés: la performance des investissements, fonds de pensions, l'allocation des actives, Sharpe ratio, la maximisation du portefeuille Markowitz mean-variance.

\section{Copyright OECD, 2008}

Applications for permission to reproduce or translate all, or part of, this material should be made to: Head of Publications Service, OECD, 2 rue André-Pascal, 75775 Paris Cédex 16, France. 


\title{
PENSION FUND PERFORMANCE
}

\author{
by Pablo Antolin ${ }^{1}$
}

\section{Introduction}

The OECD in collaboration with the World Bank and some private sector institutions ${ }^{2}$ began at the end of 2006 a study to compare investment performance of privately managed pension funds across several OECD, Latin American and Central and Eastern European (CEE) countries. ${ }^{3}$ The study first provides an analysis of aggregate investment performance by country on a risk adjusted basis using relatively standard investment performance measures. In a second stage, it seeks to build on this analysis by evaluating potential relationships between the characteristics of each pension system, individual regulatory environments and the investment performance.

This paper summarises the main studies already undertaken, ${ }^{4}$ drawing a few observations regarding data reporting and the standard analysis of investment performance, and briefly describes the next steps in extending the analysis of investment performance. Section 2 provides a description of privately managed pension funds around the world. After describing the type of pension funds included in the analysis and the regulatory environment they face, this section compares pension funds across countries according to total assets under management and asset allocation. The section ends describing the different approaches used to evaluate assets and to report investment returns. Section 3 briefly discusses the problems with the data reported by pension funds and regulators on investment returns.

\footnotetext{
${ }^{1}$ The author is principal economist of the private pension unit at the OECD. He would like to thanks delegates to the OECD Working Party on Private Pensions; André Laboul, Waldo Tapia and Juan Yermo from the OECD for their comments and assistance; and the members of the Coordination committee of the OECD - World Bank project on Pension Fund Performance for their help in putting together this report. The views expressed are the sole responsibility of the author and do not necessarily reflect those of the OECD or its member countries. The author is solely responsible for any errors.
}

2 BBVA, the Dutch Association of Industry Wide Pension Funds (VB), and ING Groep N.V. The support of the American Council of Life Insurers and the United Kingdom Department for Work and Pensions is gratefully acknowledged.

${ }^{3}$ The countries included are: Argentina, Bolivia, Brazil, Chile, Colombia, Costa Rica, El Salvador, Mexico, Peru, and Uruguay from Latin America; the Czech Republic, Estonia, Hungary, Kazakhstan, and Poland from Central and Eastern Europe; Australia, Canada, Japan, the Netherlands, Sweden, the United Kingdom, and the United States from the OECD; and Hong-Kong. The Latin America and the Central and Eastern Europe countries chosen have reformed their pensions systems over the past two decades introducing privately managed funded pensions that have reached a certain minimum size and are expected to play a significant role in the provision of retirement income. The OECD countries chosen have large privately managed funded pensions.

\footnotetext{
${ }^{4}$ This paper borrows substantially form the background documents prepared for this project by Tapia (2008a,b) and
} Walker and Iglesias (2007), in particular, sections 2 and 4, respectively. 
The next two sections discuss the results of two exploratory studies on the financial performance of pension fund systems. The first study, discussed in Section 4, provides a preliminary assessment of performance across countries using standard risk-adjusted measures (e.g. Sharpe ratios). It develops a portfolio performance analysis that seeks to provide an initial risk adjusted measure of the performance of the pension funds in nine countries for which sufficient data was available to support this kind of analysis. This has been done by estimating Sharpe ratios against several alternative specifications of low risk reference assets. This is the first exploratory study that evaluates performance in the context of a risk measure, whose principal virtue may be in highlighting the limitations of the basic risk oriented performance measure, the Sharpe ratio, to the comparative analysis of the performance of pension funds across countries and showing how to overcome some of the difficulties that will be encountered when performing this kind of analysis. The second study, summarised in Section 5, discusses the results of comparing observed pension fund returns across countries with some artificially constructed benchmark portfolios using a Markowitz portfolio optimization approach with historical data.

The paper ends discussing a few tentative policy observations that can be distilled from the work carried out so far. In particular, overcoming the limitations presented by the available data on investment performance could be a useful starting point for launching a concerted effort to develop international standards for the reporting of pension fund financial performance data that could support cross-country comparisons and more in depth performance evaluation. Finally, this section discusses some extensions to this work.

\section{Description of privately managed pension funds around the world}

This section presents an initial assessment of the financial performance of privately managed pension funds, both mandatory and voluntary, in Latin America and Central and Eastern Europe, as well as selected OECD countries (Tapia, 2008b). It provides first a comparative description of the privately managed pension funds in all the 23 countries included in the study. For this purpose, it classifies countries covered according to (1) whether pension funds included in this study are mainly occupational or personal; ${ }^{5}(2)$ the prevalence of defined benefit or defined contribution pension plans; and (3) the flexible or strict nature of investment regulations that pension plans are subject to. Secondly, it presents an international comparison of the privately managed pension funds in terms of the total value of pension assets under management, the level of assets as a percentage of the economy and the allocation of pension assets among the various asset categories and financial instruments available. Thirdly, it describes how assets are evaluated and returns calculated in each country.

The last part of this section presents an initial overview of the investment performance achieved by the privately managed pension funds. It provides annual real rates of return, annual geometric and average real returns for all countries for the period for which data is available and over the last five years. The data on returns reported are asset-weighted average gross investment returns across countries in nominal and real terms in the local currency. ${ }^{6,7}$

\footnotetext{
${ }^{5}$ According to the OECD pension taxonomy, an occupational pension plan is linked to an employment or professional relationship between the plan member and the entity that establishes the plan (plan sponsor). They may be established by employers or groups thereof (e.g. industry associations) and labour or professional associations, jointly or separately. The plan may be administered directly by the plan sponsor or by an independent entity (a pension fund or a financial institution acting as pension provider). Personal pension plans on the other hand are not linked to an employment relationship. However, the employer (e.g. Slovakia) or the State (e.g. Czech Republic) may nonetheless contribute to personal pension plans.

${ }^{6}$ It is important to use real returns when comparing pension funds' investment performance across countries as nominal returns can be higher in one country just because inflation is higher.
} 
The first step in the project was to compile data on investment performance of pension funds across countries. We collected information from each country's regulators and pension fund associations on membership, total assets under management, portfolio composition, investment return, and commissions and fees charged. We also collected information on investment regulations, asset valuation and the methodology used to calculate investment returns.

Unfortunately, the data is not complete. Data on returns is only available on a monthly basis for a few (mostly, Latin American) countries. Most countries only have annual data. The available data on commissions and fees is quite limited and it does not allow separating between the different costs, e.g. investment costs.

\section{Type of privately managed pension funds included in this paper}

The type of privately managed pension fund considered in this study varied according to the country considered (Table 1). ${ }^{8}$ There is a large variety of pension arrangements across countries. For example, pension provision through privately managed pension plans could be mandatory or voluntary, pension plans could be linked an employment relationship, making them occupational pension plans, or be personal plans. Moreover, pension provision could be organised through defined contribution or defined benefit arrangements.

Occupational pension plans are dominant in Western Europe, North America, Asia-Pacific countries and Brazil. These plans are voluntary in the United Kingdom and the United States, mandatory in Australia and quasi-mandatory (i.e. most workers are enrolled as a result of employment agreements between unions and employers) in the Netherlands. Latin American and Central and Eastern European countries, on the other hand, rely mainly in mandatory personal pension plans.

Occupational pension plans in OECD countries have traditionally been structured as DB plans. However, in recent years there has been a shift from DB to DC plans, in particular in the United Kingdom and in the United States. In these countries companies have closed or frozen their DB plans, or have transferred them to DC plans. In contrast, occupational pension plans in the Netherlands and Sweden have mainly preserved their DB character in recent years by introducing some DC features in their mainly DB plans. Occupational plans in Hong Kong and Australia offer mainly DC plans.

Unlike occupational pension provision, personal pension plans are entirely of the DC type. Similarly, the Swedish personal pension plans (the Premium Pension System) is also a fully funded DC system based on individual accounts.

\footnotetext{
${ }^{7}$ In order to compare investment performance, ideally one should compare returns net of investment management costs. Section 3 addresses these issues.

${ }^{8}$ Table 1 does not describe all the different types of privately managed pension plans available in all countries, but only those included in this study. For example, all OECD countries have voluntary personal pension plans, but they are not included in this study.
} 
Table 1. Privately managed pension funds included in this study, by country and form of provision

\begin{tabular}{|c|c|c|c|c|c|c|c|c|}
\hline \multirow{2}{*}{ 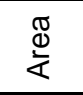 } & \multirow{2}{*}{ Country } & \multirow{2}{*}{ Date } & \multicolumn{2}{|c|}{ Mandatory } & \multicolumn{2}{|c|}{ Voluntary } & \multicolumn{2}{|c|}{ DB vs. DC } \\
\hline & & & Occupational & Personal & Occupational & Personal & $\% \mathrm{DB}$ & $\%$ DC \\
\hline \multirow{10}{*}{ 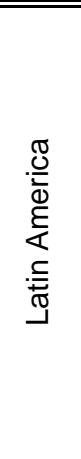 } & Argentina & 1994 & & $\sqrt{ }$ & & & $0 \%$ & $100 \%$ \\
\hline & Bolivia & 1997 & & $\sqrt{ }$ & & & $0 \%$ & $100 \%$ \\
\hline & Brazil & 1977 & & & $\sqrt{ }$ & & $0 \%$ & $100 \%$ \\
\hline & Chile & 1981 & & $\sqrt{ }$ & & & $0 \%$ & $100 \%$ \\
\hline & Colombia & 1994 & & $\sqrt{ }$ & & & $0 \%$ & $100 \%$ \\
\hline & Costa Rica & 2001 & & $\sqrt{ }$ & & $\sqrt{ }$ & $0 \%$ & $100 \%$ \\
\hline & El Salvador & 1998 & & $\sqrt{ }$ & & & $0 \%$ & $100 \%$ \\
\hline & Peru & 1993 & & $\sqrt{ }$ & & & $0 \%$ & $100 \%$ \\
\hline & Mexico & 1998 & & $\sqrt{ }$ & & & $0 \%$ & $100 \%$ \\
\hline & Uruguay & 1996 & & $\sqrt{ }$ & & & $0 \%$ & $100 \%$ \\
\hline & & & & & & & & \\
\hline \multirow{5}{*}{ 岀 } & Czech Republic & 1994 & & & & $\sqrt{ }$ & $0 \%$ & $100 \%$ \\
\hline & Estonia & 2002 & & $\sqrt{ }$ & & & $0 \%$ & $100 \%$ \\
\hline & Hungary & 1998 & & $\sqrt{ }$ & & $\sqrt{ }$ & $0 \%$ & $100 \%$ \\
\hline & Poland & 1999 & & $\sqrt{ }$ & & & $0 \%$ & $100 \%$ \\
\hline & Kazakhstan & 1998 & & $\sqrt{ }$ & & & $0 \%$ & $100 \%$ \\
\hline \multirow{3}{*}{ 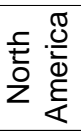 } & & & & & & & & \\
\hline & Canada & 1965 & & & $\sqrt{ }$ & & $84 \%$ & $16 \%$ \\
\hline & United States & 1947 & & & $\sqrt{ }$ & & $71 \%$ & $29 \%$ \\
\hline \multirow{3}{*}{ 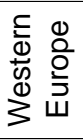 } & Netherlands & 1952 & $\sqrt{ }$ & & & & $95 \%$ & $5 \%$ \\
\hline & Sweden & $1967 / 2000$ & $\sqrt{ }$ & & $\sqrt{ }$ & & $90 \%$ & $5 \%$ \\
\hline & United Kingdom & 1834 & & & $\sqrt{ }$ & & $79 \%$ & $21 \%$ \\
\hline \multirow{3}{*}{ 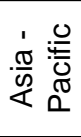 } & Australia & 1992 & $\sqrt{ }$ & & & & $10 \%$ & $90 \%$ \\
\hline & Hong Kong & 2000 & $\sqrt{ }$ & & & & $0 \%$ & $100 \%$ \\
\hline & Japan & 1944 & & & $\sqrt{ }$ & & $99 \%$ & $1 \%$ \\
\hline
\end{tabular}

\section{The regulatory investment environment}

Portfolio regulation for privately managed pension funds can follow the prudent person principle or be based on quantitative portfolio restrictions (or a combination of the two). The prudent person principle avoids the imposition of stringent portfolio limits and focuses on regulating the behaviour of investment managers. The quantitative approach prescribes various investment limits which investment managers are obliged to follow in their portfolio allocation on behalf of pension funds.

Table 2 summarizes the main differences in investment regulation across the different countries. Pension funds in Anglo-Saxon countries generally follow the "prudent man" rule, whereas Latin American and Central and Eastern Europe countries have tended to adopt a quantitative limit approach as their core regulatory mechanism. 
Table 2. Investment regulations

\begin{tabular}{|c|c|c|c|c|c|c|c|c|}
\hline 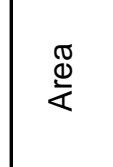 & Country & $\begin{array}{l}\text { Investment } \\
\text { only in } \\
\text { authorized } \\
\text { instrument }\end{array}$ & $\begin{array}{l}\text { Limits by } \\
\text { instruments }\end{array}$ & $\begin{array}{c}\text { Limits by } \\
\text { set of } \\
\text { instruments }\end{array}$ & $\begin{array}{l}\text { Limits by } \\
\text { issuer }\end{array}$ & $\begin{array}{l}\text { Limits by } \\
\text { risk }\end{array}$ & $\begin{array}{c}\text { Minimum } \\
\text { Retun } \\
\text { guarantees }\end{array}$ & $\begin{array}{c}\text { Foreign } \\
\text { limits }\end{array}$ \\
\hline \multirow{10}{*}{ 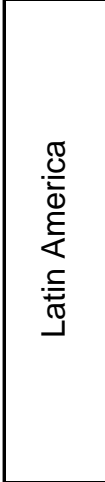 } & Argentina & $\sqrt{ }$ & $\sqrt{ }$ & & $\sqrt{ }$ & $\sqrt{ }$ & $\sqrt{ }$ & $\sqrt{ }$ \\
\hline & Bolivia & $\sqrt{ }$ & $\sqrt{ }$ & $\sqrt{ }$ & $\sqrt{ }$ & $\sqrt{ }$ & & $\sqrt{ }$ \\
\hline & Brazil & $\sqrt{ }$ & $\sqrt{ }$ & & $\sqrt{ }$ & $\sqrt{ }$ & $\sqrt{ }$ & $\sqrt{ }$ \\
\hline & Chile & $\sqrt{ }$ & $\sqrt{ }$ & $\sqrt{ }$ & $\sqrt{ }$ & $\sqrt{ }$ & $\sqrt{ }$ & $\sqrt{ }$ \\
\hline & Colombia & $\sqrt{ }$ & $\sqrt{ }$ & $\sqrt{ }$ & $\sqrt{ }$ & $\sqrt{ }$ & $\sqrt{ }$ & $\sqrt{ }$ \\
\hline & Costa Rica & $\sqrt{ }$ & $\sqrt{ }$ & $\sqrt{ }$ & $\sqrt{ }$ & $\sqrt{ }$ & & $\sqrt{ }$ \\
\hline & El Salvador & $\sqrt{ }$ & $\sqrt{ }$ & $\sqrt{ }$ & $\sqrt{ }$ & $\sqrt{ }$ & $\sqrt{ }$ & $\sqrt{ }$ \\
\hline & Peru & $\sqrt{ }$ & $\sqrt{ }$ & $\sqrt{ }$ & $\sqrt{ }$ & $\sqrt{ }$ & $\sqrt{ }$ & $\sqrt{ }$ \\
\hline & Mexico & $\sqrt{ }$ & $\sqrt{ }$ & $\sqrt{ }$ & $\sqrt{ }$ & $\sqrt{ }$ & & $\sqrt{ }$ \\
\hline & Uruguay & $\sqrt{ }$ & $\sqrt{ }$ & $\sqrt{ }$ & $\sqrt{ }$ & $\sqrt{ }$ & $\sqrt{ }$ & $\sqrt{ }$ \\
\hline \multirow{5}{*}{ 岂 } & Czech Republic & $\sqrt{ }$ & $\sqrt{ }$ & & $\sqrt{ }$ & & & $\sqrt{ }(*)$ \\
\hline & Estonia & $\sqrt{ }$ & $\sqrt{ }$ & & $\sqrt{ }$ & & & $\sqrt{ }\left({ }^{*}\right)$ \\
\hline & Hungary & $\sqrt{ }$ & $\sqrt{ }$ & & $\sqrt{ }$ & & & $\sqrt{ }(*)$ \\
\hline & Poland & $\sqrt{ }$ & $\sqrt{ }$ & $\sqrt{ }$ & $\sqrt{ }$ & & $\sqrt{ }$ & $\sqrt{ }\left({ }^{*}\right)$ \\
\hline & Kazakhstan & $\sqrt{ }$ & $\sqrt{ }$ & & $\sqrt{ }$ & & $\sqrt{ }$ & $\sqrt{ }\left({ }^{*}\right)$ \\
\hline \multirow{2}{*}{ 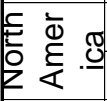 } & Canada & & $\sqrt{ }$ & & $\sqrt{ }$ & & & $\sqrt{ }$ \\
\hline & United States & & & & & & & \\
\hline \multirow{3}{*}{ 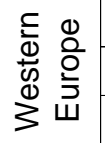 } & Netherlands & & & & & & & \\
\hline & Sweden & & $\sqrt{ }$ & & $\sqrt{ }$ & & & \\
\hline & United Kingdom & & & & & & & \\
\hline \multirow{3}{*}{ 离 $\frac{0}{\frac{0}{0}}$} & Australia & & & & & & & \\
\hline & Hong Kong & & & & & & & \\
\hline & Japan & & & & & & & \\
\hline
\end{tabular}

Source: Tapia (2007b).

These choices may be justified by the relative development of their respective capital markets. For example, the relatively under-developed capital market in Latin American and Central and Eastern Europe countries explain partially the strict investment regulation in these countries. On the contrary, pension funds in countries with better-developed capital markets generally require only a light regulatory framework. Additionally, mandatory retirement savings arrangements put more responsibility on the government than voluntary arrangements do. Under mandatory arrangements, governments assume a higher degree of responsibility and hence there is a 'stronger' case for a more stringent regulatory approach. Finally, countries with defined benefit pensions are in less need for detailed investment regulations as employers stand behind the promised pension benefit. This contrast with the detailed regulation of portfolio in defined contribution pensions, whose value depend more closely on fund performance.

\section{Total assets and asset allocation}

The total amount of assets held by privately managed pension funds as a share of GDP varies significantly across the countries studied (Figure 1). By the end of 2005, total assets in the 23 countries covered in this study amounted to over US\$ 15 billion, ranging from around 100 percent of GDP in some 
OECD countries to less than 10 per cent in most Latin American and CEE countries. The relatively small size of accumulated assets in Latin America and CEE countries is partly explained by the recent implementation of their private systems, which, with the exception of Chile, have less than ten years.

Figure 1. Total assets and its allocation, 2005.

\section{A. Assets as percentage of GDP}

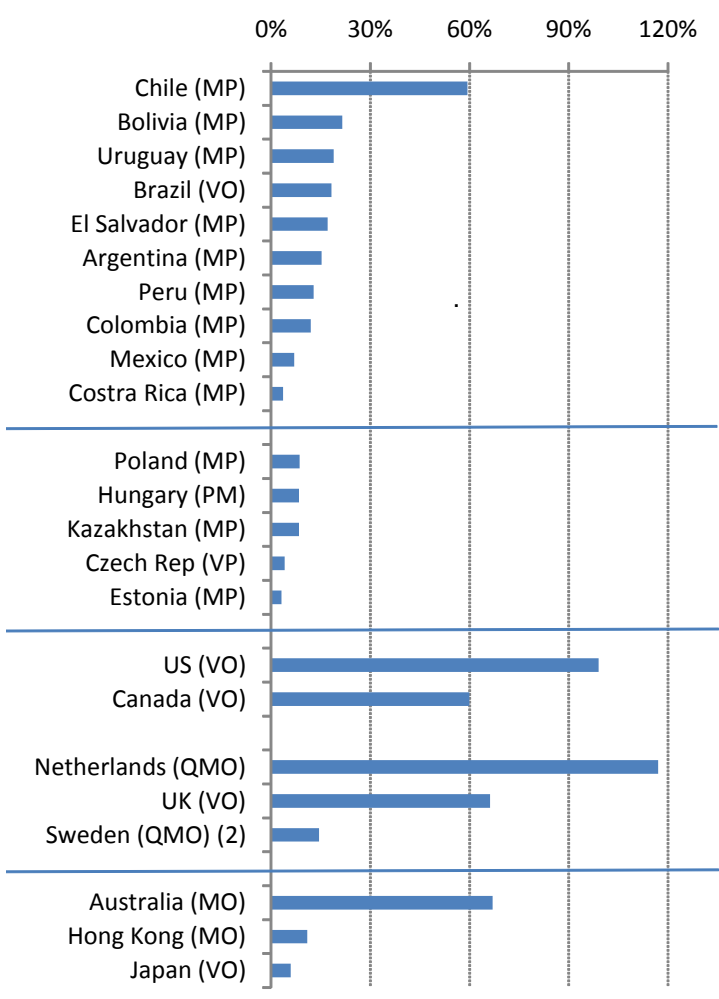

B. Equites and bonds as $\%$ of total assets ${ }^{1}$

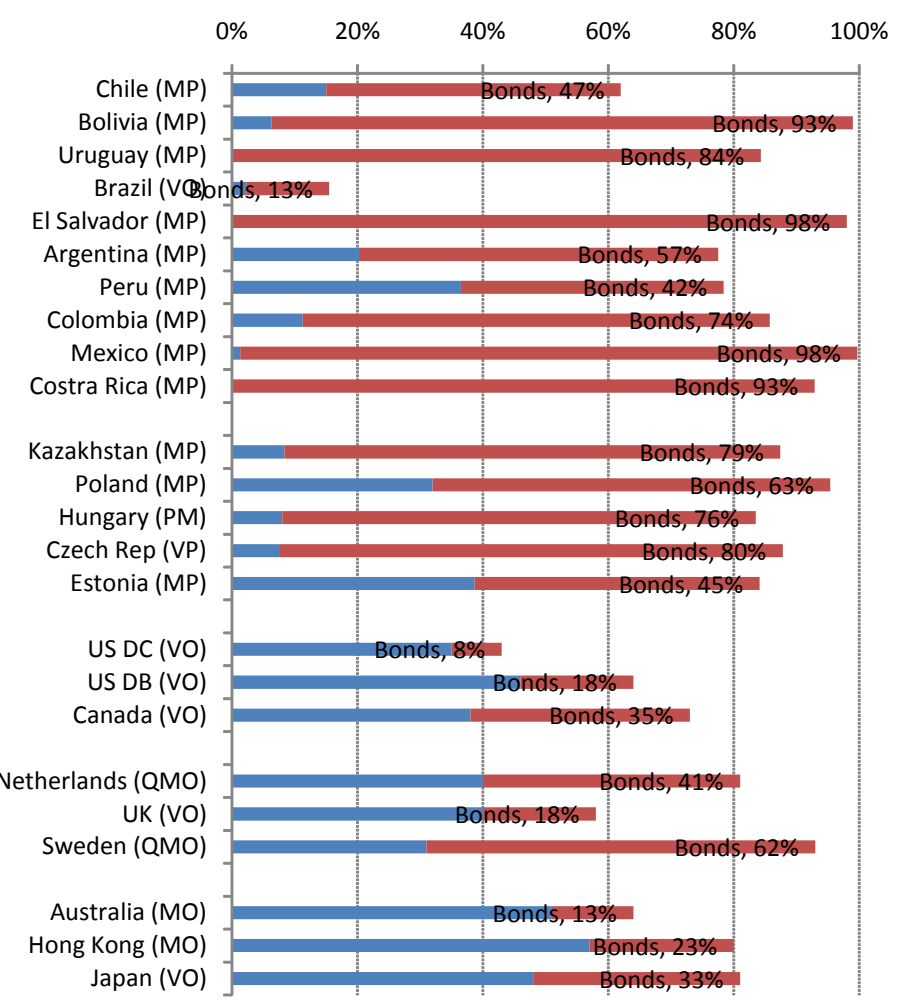

Source: OECD, Global Pensions Statistics

Notes: 1 . Share in bonds provided. The other bar correponds to the share in equity. The difference to $100 \%$ corresponds to investment in other asset classes. 2. Include information only from ALECTA.

$\mathrm{MP}=$ mandatory personal plans, $\mathrm{VP}=$ voluntary personal plans, $\mathrm{MO}=$ mandatory occupational plans, $\mathrm{VO}=$ voluntary occupational plans, $\mathrm{QMO}=$ quasi-mandatory occupational plans.

Asset allocation between equity and bonds shows a wide dispersion among different countries (Figure 1). In some countries, pension funds hold its entire portfolio in fixed income securities whereas in other countries funds have none or only few fixed income holdings. Equity investments also vary wildly from $0 \%$ to over $100 \%$ of the asset allocation depending of the country.

These differences in asset allocation can be partly explained by the liability structure (DB occupational plans), and by investment regulations (DC personal plans). Other variables affecting strategic asset allocation could include factors such as the age structure of members, ${ }^{9}$ historical reasons, sponsor's own preferences or the expected capital market return.

\section{Approaches used to value pension funds' assets and to report investment returns}

In order to assess pension fund performance, it is necessary to examine how assets are valued and the approach used across countries to report investment returns. Such an exercise can help identify possible

\footnotetext{
${ }^{9}$ Pension funds with younger participants tend to have more equity exposure, whereas more mature pension funds tend to have more fixed income investments.
} 
limitations when comparing reported data on investment returns. Table 3 summarises the asset valuation approaches used by pension funds in the countries covered.

The majority of occupational pension systems (i.e. OECD countries) included in this paper use a valuation methodology based on the market value. In Latin America, there are compulsory regulations in every country for the valuation of pension assets (Tapia, 2008b). Nevertheless, they are mostly based on market prices. Among Central and Easter European countries, valuation of pension fund assets at market prices is the general rule except in the Czech Republic and Estonia that have followed different criteria for valuing part of their portfolio.

Table 3. Asset valuation methodologies across countries

\begin{tabular}{|c|c|c|}
\hline$\stackrel{\mathbb{\varpi}}{\stackrel{\varpi}{<}}$ & Country & Valuation Methodology \\
\hline \multirow{10}{*}{ 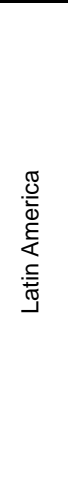 } & Argentina & Market value except certain public bonds, which are valued at "book value". \\
\hline & Bolivia & Market value. \\
\hline & Brazil & Market value except certain bonds, which are valued at "book value". \\
\hline & Chile & Market value. \\
\hline & Colombia & $\begin{array}{l}\text { Market value except certain variable income securities (equities), which are valued according to a } \\
\text { liquidity index during the valuation date. }\end{array}$ \\
\hline & Costa Rica & $\begin{array}{l}\text { Market value except for those instruments which a period of maturity less than } 180 \text { days, where the } \\
\text { valuation at market price is optional. }\end{array}$ \\
\hline & El Salvador & Market value. \\
\hline & Mexico & $\begin{array}{l}\text { Market value. However, due to practical limitations (e.g. iliquid markets), some securities are } \\
\text { marked-to-model. }\end{array}$ \\
\hline & Peru & Market value. \\
\hline & Uruguay & Market value. \\
\hline \multirow{5}{*}{ 岂 } & Czech Republic & $\begin{array}{l}\text { Market value except financial instruments held to maturity, securities of a collective investment fund } \\
\text { or financial instruments not actively traded on a market, for which the valuation procedure is the } \\
\text { average price of executed transactions. }\end{array}$ \\
\hline & Estonia & $\begin{array}{l}\text { Market value except cash and deposits with credit institutions, which are valued according to their } \\
\text { book value. }\end{array}$ \\
\hline & Hungary & Market value. \\
\hline & Poland & Market value. \\
\hline & Kazakhstan & Market value. \\
\hline \multirow{2}{*}{ 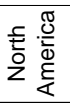 } & Canada & Market value. \\
\hline & United States & Market value. \\
\hline \multirow{3}{*}{ 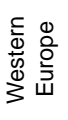 } & Netherlands & Market value. \\
\hline & Sweden & Market value. \\
\hline & United Kingdom & Market value. \\
\hline \multirow{3}{*}{ 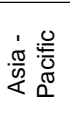 } & Australia & Market value. \\
\hline & Hong Kong & Market value. \\
\hline & Japan & Market value. \\
\hline
\end{tabular}

Additionally, the approach to report investment returns varies across countries (Tapia, 2008a,b) Personal pension plans in Latin American and Central and Eastern European countries have detailed regulations defining the methodology for calculating returns. This regulation is usually established by the supervisory authority, either as the official calculation or as a control, verifying the asset managers' calculations. Calculation methods are even more important in those countries that regulate the performance of portfolio through minimum or relative rate-of-return guarantees. On the contrary, the definition of and criteria for calculating and reporting total return among Western Europe, North America and Asia-Pacific countries is stated in the investment policy established by the asset manager. Another difference in return calculation methodologies across countries is the treatment of management fees. Most Latin American countries report returns gross of fees, while some OECD countries report them net of some fees (e.g. administrative fees). 
As a result of differences in reporting frameworks and valuation methodologies, as well as differences in the regulatory environment, in the time-frame of their pension systems and, most importantly, because of differences in investment efficiency and idiosyncratic characteristics of each country pension system, ${ }^{10}$ it is meaningless to compare investment performance across countries using just reported returns.

Nevertheless, it is important to see in isolation how investment returns have evolved in the different countries. In this regard, Table 4 reports average real returns (nominal returns in local currency less price inflation) for the countries examined in this report since the system has been in place and for the last fiveyear period. ${ }^{11}$

Table 4. Basic statistical information on real investment returns by country ${ }^{1}$

\begin{tabular}{|c|c|c|c|c|c|c|}
\hline \multirow[b]{2}{*}{ Countries } & \multicolumn{4}{|c|}{ Entire period } & \multicolumn{2}{|c|}{ Dec 2000 - Dec 2005} \\
\hline & $\begin{array}{l}\text { Data } \\
\text { since }\end{array}$ & $\begin{array}{c}\text { Geometric } \\
\text { Mean Return }\end{array}$ & $\begin{array}{c}\text { Arithmetic } \\
\text { Mean Return }\end{array}$ & $\begin{array}{l}\text { Standard } \\
\text { Deviation }\end{array}$ & $\begin{array}{c}\text { Average } \\
\text { Return }\end{array}$ & $\begin{array}{l}\text { Standard } \\
\text { Deviation }\end{array}$ \\
\hline \multicolumn{7}{|c|}{ Latin America } \\
\hline Argentina (MP) & 1995 & 9.7 & 10.2 & 11.6 & 7.3 & 15.0 \\
\hline Bolivia (MP) & 1998 & 10.1 & 10.2 & 4.6 & 9.6 & 5.9 \\
\hline Brazil (VO) & 1995 & 5.7 & 5.9 & 6.3 & 2.7 & 4.8 \\
\hline Chile (MP) & 1982 & 9.5 & 9.8 & 8.5 & 6.1 & 2.7 \\
\hline Costa Rica (MP) & 2002 & 5.8 & 5.9 & 3.3 & 4.6 & 3.3 \\
\hline El Salvador (MP) & 1999 & 5.7 & 5.8 & 4.5 & 3.7 & 2.5 \\
\hline Mexico (MP) & 1998 & 7.3 & 7.3 & 3.8 & 6.5 & 4.0 \\
\hline Peru (MP) & 1994 & 14.3 & 14.6 & 8.8 & 15.0 & 6.1 \\
\hline Uruguay (MP) & 1997 & 14.7 & 15.3 & 13.0 & 19.2 & 16.4 \\
\hline \multicolumn{7}{|c|}{ Central and Eastern Europe } \\
\hline Czech Republic (VP) & 1995 & 1.0 & 1.1 & 1.6 & 1.5 & 1.5 \\
\hline Estonia (MP) & 2002 & 5.2 & 5.3 & 4.5 & 4.1 & 4.5 \\
\hline Hungary (MP) & 1998 & 2.3 & 2.4 & 5.4 & 3.1 & 5.8 \\
\hline Kazakhstan (MP) & 1999 & 7.9 & 8.4 & 12.7 & 2.3 & 5.3 \\
\hline Poland (MP) & 2000 & 8.7 & 8.7 & 4.9 & 9.6 & 4.8 \\
\hline \multicolumn{7}{|c|}{ North America } \\
\hline Canada (VO) & 1990 & 6.2 & 6.2 & 3.2 & 3.5 & 1.9 \\
\hline United States (DB) (VO) & 1988 & 7.1 & 7.5 & 9.6 & 1.5 & 13.9 \\
\hline United States (DC) (VO) & 1988 & 6.1 & 6.5 & 8.7 & 0.7 & 13.1 \\
\hline \multicolumn{7}{|c|}{ Western Europe } \\
\hline Netherlands (QMO) & 1993 & 6.1 & 6.4 & 8.2 & 2.0 & 10.3 \\
\hline Sweden (QMO) & 1990 & 6.2 & 6.6 & 9.7 & 1.0 & 10.4 \\
\hline United Kingdom (VO) & 1982 & 8.7 & 9.5 & 12.5 & 1.9 & 16.5 \\
\hline \multicolumn{7}{|c|}{ Asia-Pacific } \\
\hline Australia (MO) & 1990 & 8.9 & 9.1 & 5.7 & 4.9 & 8.4 \\
\hline Hong Kong (MO) & 2000 & 2.1 & 2.7 & 13.2 & 1.7 & 13.2 \\
\hline Japan (VO) & 1990 & 3.4 & 3.7 & 8.9 & 4.8 & 13.9 \\
\hline
\end{tabular}

It is interesting to notice that by assessing average rate of return in the last five years (2000-2005), for which there is data for all countries, against the volatility of these returns as measured by the standard deviation, most countries have had relative low average returns and relative low volatility (Figure 2). However, some countries achieved relatively high returns with relatively high volatility (Uruguay and, to

${ }^{10}$ Certain of these aspects are specific to pension funds, such as the investment horizon and the existence of future commitments; others are specific to the regulatory framework in each country, including the investment regulatory regime, the criteria for valuing portfolio and the methodology used for pension funds to calculate investment returns; and finally, there are aspects related to the level of development and the performance of the local financial market. See Tapia (2008a) for more information.

${ }^{11}$ Tapia (2008b) reports the complete time series of investment returns, detailed basic statistics and a detailed description of the different sources of information used from each country. 
some extend Argentina and Peru), others achieved relative high returns with low relatively volatility (Bolivia and Poland), and, finally, Hon-Kong, Japan, the United Kingdom and the United States had very low average returns over the 5-year period and relatively high volatility. Finally, the volatility (i.e. standard deviation) of returns in OECD countries is larger than in non-OECD countries.

Figure 2: Average annual return and standard deviation, December 2000-December 2005.

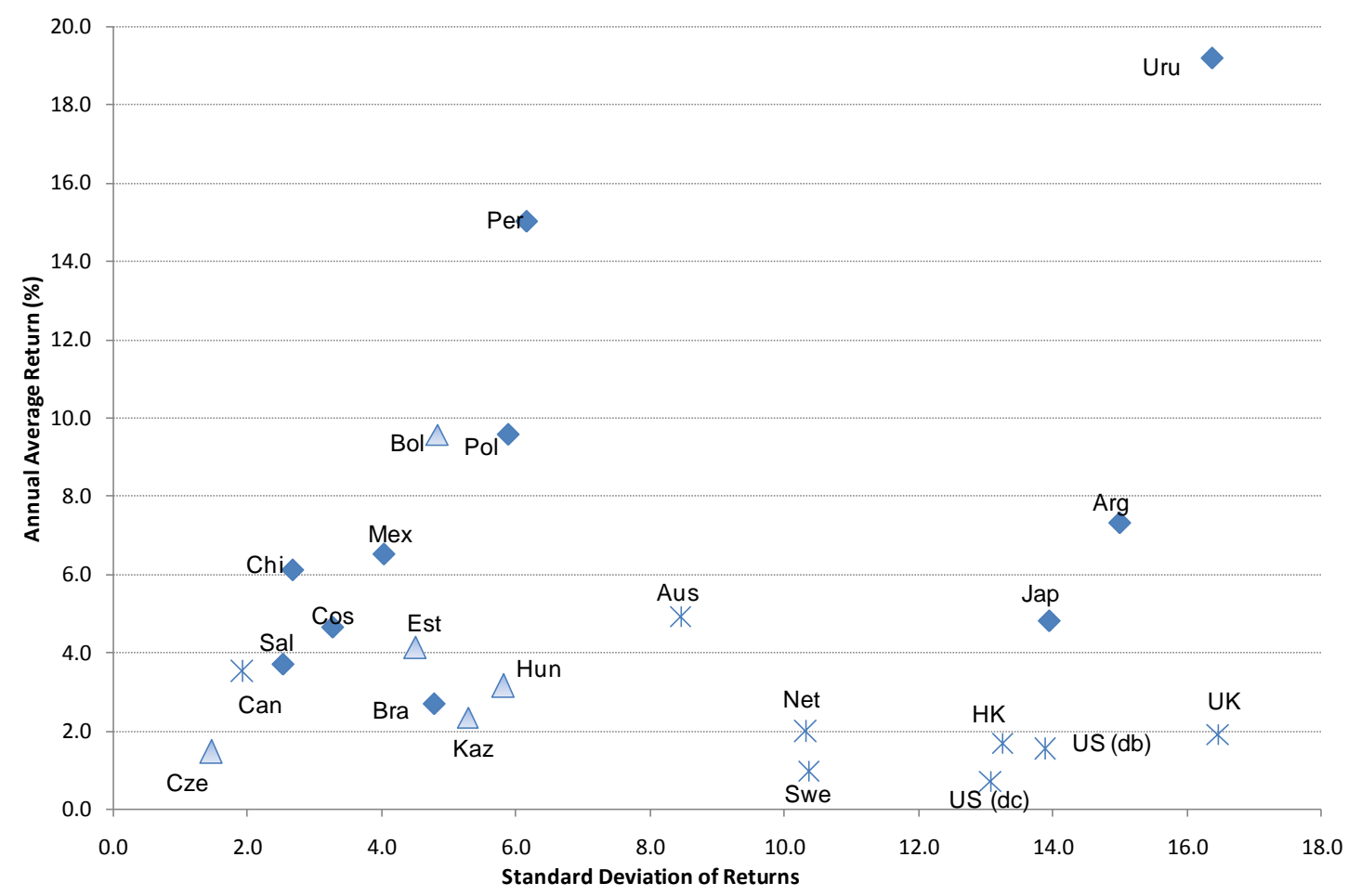

Source: Tapia (2008b)

\section{Additional problems with the data reported on investment returns}

Unfortunately, the data available from pension funds and regulators suffer of several biases that render any comparison attempt across countries hazardous. The previous section already addressed some of the problems posed for any meaningful comparison across countries: different valuation methodologies, differences in expenses charged to the funds, and differences in the legal environment (e.g. investment restrictions). This section briefly discuses some additional problems related to the way investment returns are averaged across pension funds and over the year, which introduces several biases.

The data available from pension funds and regulators suffer the problems of "lagged aggregate weights", "weighted average share values", "non-overlapping synchronized portfolio, benchmark and risk free returns", "clear portfolio composition separation between different asset classes" and "survival bias".

The "lagged aggregate weights" is linked to the performance bias. This bias arises when calculating the aggregate performance of a group of pension funds or of a country; they use the relative weight of each pension fund at the end of the period. This will lead to an important bias against (in favour of) pension funds that have experience a lower (higher) performance over the period under analysis. This bias can be overcome by using lagged values. Calculations of returns should use as weights those at the beginning of every month, quarter or year. Additionally, when averaging returns over different period (e.g. monthly or quarterly) the weights need to vary over time as well ("variable weights") to avoid biases. In this regard, 
the problem of "weighted average share values" stems from using constant weights across time to calculate returns.

Additionally, some countries (e.g. Colombia, Costa Rica, and El Salvador) provide overlapping returns (e.g. a 12-month moving average return). Returns reported in this manner cannot be worked back into monthly, quarterly or annual rates of return. Moreover, they will always suffer the problem of constant weights.

One of the more severe problems when comparing investment performance across pension funds and countries is the lack of a clear portfolio composition separation between the different asset classes. This renders the task of calculating hypothetical portfolios benchmarks using different asset classes as a near impossible task.

The data reported by pension funds and regulators also suffer from the survival bias. This bias arises when constructing weighted averages across pension funds using only data from existing funds. Using only funds that remain in business without accounting for those funds that did not survive over the period analysed will bias upwards the returns. This bias will make impossible to compare investment performance across countries and pension funds groupings when pension funds' survival rates differ.

Finally, the analysis that follows compares asset-weighted average gross investment returns across several countries gross of investment management costs. Ideally, it should compare returns net of investment management costs. Pension funds incur in many costs, among them administrative costs, marketing and advertising costs, as well as investment management costs. ${ }^{12}$ However, only costs associated with the investment activities of pension funds should be netted out in order to produce a comparison of investment performance. ${ }^{13}$ Unfortunately, there is a lack of consistent and widely available data on investment management costs. In most countries, supervisory entities only publish information on total charges to members and do not provide a breakdown of different costs. Moreover, countries charge fees following different approaches. ${ }^{14,15}$

The next section performs an exploratory study of financial performance adjusting by risk for those countries where there is enough information available to make the calculations comparable in terms of valuation methodologies, expenses charged to the funds, and legal restrictions. However, the different biases discussed above may remain.

\footnotetext{
${ }^{12}$ Marketing and advertising costs arise mainly in retail pension systems (i.e. personal pension plans).
}

${ }^{13}$ Most of the other costs depend on the type of private pension system in place. For example, pension funds in countries where participation in private pension funds is quasi-compulsory and employment agreements already assign individuals to different pension funds, have small costs related to attracting people, such as promotion and advertising. On the other hand, pension funds in countries with compulsory systems where individuals are relatively free to choose among different pension funds available, have large costs in attracting members. Therefore, netting out total costs leads to comparing pension systems' performance instead of investment performance of privately managed pension funds.

${ }^{14}$ Pension funds tend to charge members a fee to cover all their costs. However, different pension systems charge fees in different ways. For example, in most Latin American countries, pension funds charge a fee to cover overall costs as a percentage of member's contributions. In some OECD countries, e.g. The Netherlands, the fees are a percentage of the amount of assets under managements.

${ }^{15}$ The Coordination Committee of the OECD - World Bank project has commissioned a study that will review of the literature on investment management costs available and, most importantly, it will approximate this costs as a share of total costs incurred by privately managed pension funds. 


\section{An exploratory study of the financial performance of pension fund systems around the world using Sharpe ratios and attribution analysis}

This section discusses the main issues and results of a portfolio performance analysis of pension funds that consists in estimating Sharpe ratios against several alternative specifications of low risk reference assets and in applying Sharpe's (1992) attribution methodology (Walker and Iglesias, 2007). In order to perform these calculations, the study attempts to correct for some of the biases mentioned above, for those countries for which data may lent itself to such corrections.

The report first addresses the limitations and strengths of using Sharpe ratios (Sharpe, 1966) to assess portfolio performance. It concludes that Sharpe ratios may not be meaningful in comparing portfolio performance across countries, but they address the question on whether the different pension systems have beaten their own benchmarks or low risk references. Secondly, the report estimates Sharpe ratios using four alternative specifications for the risk free asset: a short-term local rate, a long-term local rate, a shortterm US rate (T-bill), and a long-term US rate (T-bonds). Thirdly, the report calculates another performance measure using Sharpe's empirical attribution analysis (Shape, 1992). The main conclusion from this report is that for those countries with appropriate data, privately managed pension funds have obtained a positive premium given the level risk when comparing at least with the short-term alternative investment instrument.

\section{Limitations and strengths of using Sharpe ratios}

Sharpe ratios measure the excess return (or risk premium) per unit of risk in an investment strategy. Consequently, if every investor combines a single riskless asset (supposedly well defined) with the portfolio whose performance is being evaluated, and that the relevant risk measure is the same for all investors (volatility), then the unique measure of performance that should be used to rank alternative investment opportunities is the so-called Sharpe Ratio. Consequently, those pension funds with an investment strategy with the highest Sharpe ratio are the best performers.

Unfortunately, this is only valid under certain assumptions which are not always fulfilled. For every investor to view risk in the same way and for the Sharpe ratio to provide a significant ranking, the following assumptions need to hold: (1) there are no short-sale restrictions for the risk free asset; (2) all investors have the same planning horizon; (3) there are no other sources of wealth; and (4) consumption goods prices are uncorrelated with asset returns. Under these assumptions investors should choose the portfolio with the highest Sharpe Ratio, as illustrated by the line with the steepest slope in figure 1, since it allows investors to maximize expected return per unit of total risk, and preferences are assumed to be increasing in expected returns and decreasing in volatility. The Sharpe Ratio measures the slope coefficient.

Figure 3: The Sharpe Ratio

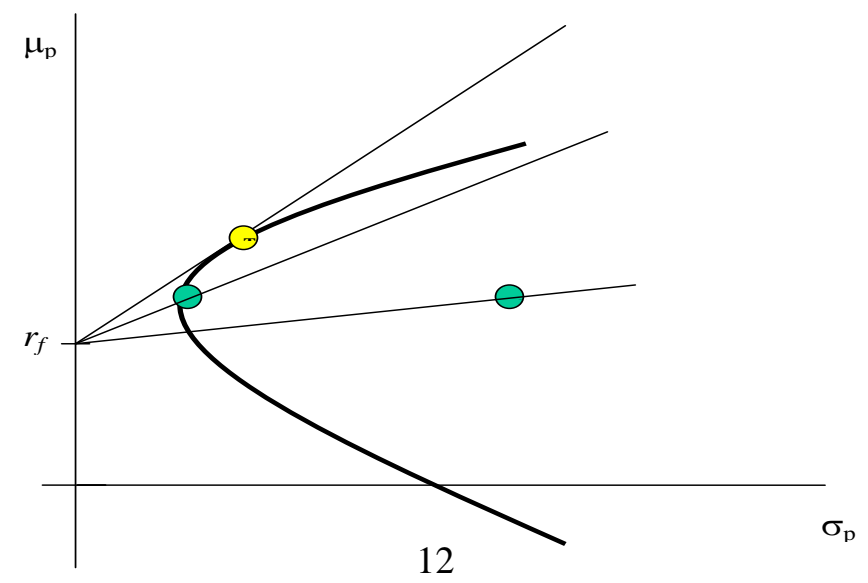


Sharpe ratios can be expected to vary widely over time (Walker and Iglesias, 2007) and across asset classes. This implies that comparing pension funds that have invested differently or comparing different time frames may not always be meaninful, just as it cannot be meaningfully said ex-ante that investing in stocks is better or worse than investing in bonds, as it depends, among other things, on risk aversion and the investment horizon.

Additionally, the assumptions required for the Sharpe ratio to be a valid ranking instrument are particularly unwarranted when comparing across countries. First, it is not the same investor who is comparing different alternatives, and we cannot compare welfare across countries. Second, foreign exchange risk and real interest rate risk are viewed differently in different countries (see for example Walker, 2006, 2007). Third, the very meaning of the Sharpe ratio is unclear when a riskless rate does not exist or when proxies for it are used. But even if riskless rates do exist, comparability across countries is questionable.

Nevertheless, one can meaningfully assess, using Sharpe ratios, whether the different pension systems have obtained a risk premium or have beaten their own benchmarks or low risk references.

\section{Calculating Sharpe ratios}

In order calculate Sharpe ratios, one need to find the riskless asset alternative. As explained above, the Sharpe ratio is a valid measure for comparing alternative risky portfolios which may be combined with the riskless asset. Unfortunately, this relative simple concept has many practical complications: (1) a truly riskless asset may not exist in some countries; (2) there are differences in the investment horizon; and (3) should the calculation consider a foreign currency asset as a riskless asset, such a T-bill or a T-bond.

Table 5 below reports estimated Sharpe ratios using four alternative specifications for the risk free asset: a short-term local rate, a long-term local rate, a short-term US rate (T-bill), and a long-term US rate (T-bonds), for the cases where the alternative exists. Sharpe ratios are positive and statistically significant in most countries when comparing to their short-term alternatives, either local or foreign (columns A and C). However, they are statistically non-significant when comparing with their long-term alternatives, except in Hungary, and to some extent Chile (depending of the pension fund) and Poland.

\section{Sharpe's empirical attribution analysis}

To complement the Sharpe ratios, the report calculates an additional performance measure using Sharpe's empirical attribution analysis (Sharpe, 1992) for average and rolling weights (Table 5). This measure detects the value added by a portfolio manager via selectivity and/or market timing, and it avoids some of the biases discussed previously. For its implementation, the analysis considers as asset classes local T-Bills or deposits, local T-Bonds, both in local currency, local equity, US T-Bills, US-T-Bonds and Global equity. The methodology searches for non-negative portfolio (index) weights that minimize the variance of $r_{p t}-r_{B t}$, where $r_{p t}$ represents the pension fund return and $r_{B t}$ is the return of the weighted average of index returns. This methodology is similar to a least squares regression, subject to non-negativity constraints on the coefficients. The weights are represented by the $\beta$ 's in equation (1) below. In Sharpe's words, $r_{B t}$ is the Style return. An interesting application, as suggested by Sharpe, is to estimate the portfolio weights with information until $t$, and then use them out of sample to weigh the index returns in $t+1$, and then repeat the estimation until $t+1$ to apply it to index returns in $t+2$. These are rolling estimates. In both cases (for the in- and out-of sample or rolling estimates), the value added is estimated as the return difference, called Selection return, represented by the Alpha in equation (1). ${ }^{16}$

\footnotetext{
${ }^{16}$ This methodology yields as a particular case Jensen's Alpha, when only short-term fixed income and stocks are considered.
} 


$$
\overline{r_{p t}}=\alpha_{p}+\sum_{k} \beta_{p k(t-q)} \overline{r_{k t}} \equiv \alpha_{p}+\overline{r_{B t}} \equiv \text { Selection }+ \text { Style }
$$

This methodology has several advantages: it considers endogenous benchmarks of similar "style" to the evaluated portfolio; the rolling approach allows portfolio weights to change over time, and since these are in principle observable, the benchmark can be replicated; finally, the use of several benchmarks is more likely to yield "mean-variance efficient" combined benchmarks. Notice that if a portfolio invests in an asset class not considered among the benchmarks (local corporate bonds, for example), the approach assumes that a combination of the included benchmarks (government bonds plus local stocks, for example) should yield similar results. This is an application of the "replicating portfolio" concept.

Table 5 provides as well the results of calculating Sharpe's empirical attribution measure using either average weights or rolling weights. The attribution measure, whether using average or rolling weights, is statistically significant in most countries.

The main conclusion from this analysis is that privately managed pension funds have obtained a positive risk premium, have added value, with respect, at least, to the low risk short-term alternatives. 
Table 5. Performance measures

\begin{tabular}{|c|c|c|c|c|c|c|c|c|c|c|c|}
\hline \multicolumn{8}{|c|}{ Sharpe Ratios } & \multicolumn{4}{|c|}{ Attribution } \\
\hline \multicolumn{2}{|c|}{ A. STL } & \multicolumn{2}{|c|}{ B. LTL } & \multicolumn{2}{|c|}{ C. STU } & \multicolumn{2}{|c|}{ D. LTU } & \multicolumn{2}{|c|}{ E. ATT AVG } & \multicolumn{2}{|c|}{ F. ATT ROLL } \\
\hline Statistic & t-test & Statistic & t-test & Statistic & t-test & Statistic & t-test & Statistic & t-test & Statistic & t-test \\
\hline \multicolumn{12}{|c|}{ Argentina } \\
\hline \multicolumn{12}{|c|}{ TOTAL RWA SEP1994-DEC2005 } \\
\hline 0.11 & 1.31 & & & 0.01 & 0.17 & -0.03 & -0.30 & 0.00 & 1.28 & 0.00 & -0.20 \\
\hline \multicolumn{12}{|c|}{ TOTAL AVG Q SEP1994-MAY2007 } \\
\hline 0.13 & 1.60 & & & 0.03 & 0.35 & -0.01 & -0.09 & 0.00 & 1.42 & 0.00 & -0.32 \\
\hline \multicolumn{12}{|c|}{ TOTAL AVG Q JUN2004-MAY2007 } \\
\hline & & & & & & & & & & 0.01 & 2.86 \\
\hline \multicolumn{12}{|c|}{ Bolivia } \\
\hline & & & & BOLIVIA & OTAL JL & UN1997-M & Y2007 & & & & \\
\hline 0.69 & 6.81 & & & 0.99 & 8.87 & 0.07 & 0.72 & & & & \\
\hline & & & & & Chi & & & & & & \\
\hline & & & & CHILI & A_JUL2 & 002 -FEB 2 & & & & & \\
\hline 0.60 & 3.55 & 0.43 & 2.66 & 0.57 & 3.40 & 0.50 & 3.01 & 0.01 & 2.56 & & \\
\hline & & & & CHILI & B_JUL2 & 002 -FEB 20 & & & & & \\
\hline 0.63 & 3.66 & 0.38 & 2.34 & 0.55 & 3.30 & 0.46 & 2.83 & 0.00 & 2.45 & & \\
\hline & & & & CHIL & C_SEP1 & 986-FEB20 & & & & & \\
\hline 0.21 & 3.57 & 0.07 & 1.05 & 0.11 & 1.89 & 0.00 & 0.03 & 0.00 & 0.96 & 0.00 & 2.60 \\
\hline & & & & CHILI & D_JUL2 & 002 -FEB 2 & & & & & \\
\hline 0.63 & 3.70 & 0.34 & 2.11 & 0.52 & 3.12 & 0.46 & 2.81 & 0.00 & 3.11 & & \\
\hline & & & & CHIL & E_JUN2 & 2000-FEB 20 & & & & & \\
\hline 0.48 & 3.81 & -0.26 & -2.11 & 0.19 & 1.58 & 0.04 & 0.37 & 0.00 & 2.08 & 0.00 & 1.03 \\
\hline & & & & CHILE T & DTAL_SE & EP1986-FEI & 2006 & & & & \\
\hline 0.18 & 2.72 & 0.07 & 1.13 & 0.22 & 3.31 & 0.10 & 1.54 & 0.00 & 1.07 & 0.00 & 2.70 \\
\hline & & & & & Estor & & & & & & \\
\hline & & & & ESTONI & BAL-JU & L2002-DEC & 2005 & & & & \\
\hline 0.47 & 2.89 & -0.08 & -0.54 & 0.33 & 2.05 & 0.20 & 1.30 & 0.00 & 3.32 & & \\
\hline & & & & ESTONIA & CONS-JL & UL2002-DE & 2005 & & & & \\
\hline 0.21 & 1.36 & -0.27 & -1.70 & 0.21 & 1.34 & 0.11 & 0.73 & 0.00 & 1.04 & & \\
\hline & & & & ESTONIA & PROG-JL & UL2002-DE & C2005 & & & & \\
\hline 0.44 & 2.71 & 0.06 & 0.42 & 0.41 & 2.58 & 0.27 & 1.74 & 0.01 & 3.32 & & \\
\hline & & & & ESTONIA & ГOTAL-J & UL2002-D & C2005 & & & & \\
\hline 0.47 & 2.88 & 0.01 & 0.07 & 0.38 & 2.36 & 0.25 & 1.58 & 0.00 & 3.28 & & \\
\hline & & & & & Hung & ary & & & & & \\
\hline & & & HUN & NGARY QL & ARTERL & Y-JUN199 & -MAR200 & & & & \\
\hline 0.30 & 1.76 & 0.42 & 2.41 & 0.50 & 2.81 & 0.37 & 2.12 & 0.02 & 3.16 & & \\
\hline & & & & & Mexi & & & & & & \\
\hline & & & $\mathrm{ME}$ & XICO TOT & AL AVG & Q-JUL199 & -DEC200 & & & & \\
\hline 0.30 & 2.78 & -0.07 & -0.62 & 0.21 & 1.98 & 0.08 & 0.73 & 0.00 & 2.81 & 0.00 & 2.54 \\
\hline & & & & EXICO TO & AL RVW & J-AUG1997 & DEC2005 & & & & \\
\hline 0.35 & 3.37 & -0.06 & -0.63 & 0.23 & 2.24 & 0.10 & 1.02 & 0.00 & 3.41 & 0.00 & 4.66 \\
\hline & & & & & he Neth & erlands & & & & & \\
\hline & & & & NETHERL & ANDS AI & NNUAL 198 & 62006 & & & & \\
\hline 0.39 & 1.73 & 0.14 & 0.60 & 0.45 & 1.92 & 0.16 & 0.69 & 0.01 & 2.57 & & \\
\hline & & & & & Per & & & & & & \\
\hline & & & & ERU AVG & QUOTA- & OCT1993-I & EC2005 & & & & \\
\hline 0.12 & 1.45 & & & 0.27 & 3.20 & 0.10 & 1.26 & 0.00 & 1.72 & 0.00 & 1.40 \\
\hline & & & & PERU I & WA-JAN & 2001-DEC & 005 & & & & \\
\hline 0.40 & 2.96 & & & 0.54 & 3.88 & 0.24 & 1.86 & 0.00 & 4.31 & 0.01 & 2.11 \\
\hline & & & & & Pola & & & & & & \\
\hline & & & & POLAND & OTAL-M & IAY1999-D & $\mathrm{C} 2005$ & & & & \\
\hline 0.11 & 1.00 & 0.02 & 0.21 & 0.23 & 2.06 & 0.16 & 1.40 & 0.00 & 2.09 & 0.00 & 0.57 \\
\hline & & & & & Inited $K i$ & ingdom & & & & & \\
\hline & & & UNITED & KINGDON & QUART & ERLY MA & $1992 \mathrm{DE}$ & EC2005 & & & \\
\hline 0.21 & 1.58 & 0.10 & 0.80 & 0.28 & 2.10 & 0.13 & 1.00 & 0.004 & 3.43 & 0.01 & 4.12 \\
\hline & & & & & Urugl & uay & & & & & \\
\hline & & & & URUGL & AY-AUG & 1996-MAY & 2007 & & & & \\
\hline 0.13 & 1.47 & & & 0.18 & 1.99 & 0.09 & 1.01 & & & & \\
\hline
\end{tabular}




\section{Comparing investment returns using some artificially constructed benchmark portfolios}

This section reports preliminary results of on-going work assessing the investment performance of privately managed pension funds against artificially constructed country-specific benchmarks. This is an initial benchmarking exercise that uses a Markowitz mean-variance (MV) portfolio maximization approach with historical data. That is, it compares the investment performance of a pension fund with that of an artificially constructed benchmark portfolio whose asset mix would have produced the highest (mean) return for a given level of risk (variance). As a result, it calculates, with hindsight, how much better pension funds could have done, given past market returns, for a specific level of risk.

This on-going work will also examine how well funded systems have performed compared to the theoretical alternative of a publicly managed PAYG. For this purpose, the report compares the observed returns of pension funds against the returns of a benchmark portfolio that it is highly correlated with GDP growth. ${ }^{17}$

Additionally, this on-going work takes into account that pension funds operate under different regulatory environments and, as result, they may be subject to specific investment constraints. In order to take into account differences across countries in investment restrictions, this work compares observed returns with those of two artificially constructed country specific benchmark portfolios. One whose asset mix would have produced the highest (mean) return for a given level of risk (variance), and fulfils each country investment constraints; and second one whose asset mix would have produced the highest (mean) return for a given level of correlation with GDP growth, and fulfils each country investment constraints.

Therefore, this study uses four hypothetical benchmarks to assess the performance of privately managed pension funds in each country: (A) an artificially constructed benchmark portfolio whose asset mix would have produced the highest (mean) return for a given level of risk (variance); (B) an artificially constructed benchmark portfolio whose asset mix would have produced the highest (mean) return for a given level of risk (variance), fulfilling each country specific investment constraints; (C) an artificially constructed benchmark portfolio whose asset mix would have produced the highest (mean) return for a given correlation with GDP growth; and (D) an artificially constructed benchmark portfolio whose asset mix would have produced the highest (mean) return for a given correlation with GDP growth, fulfilling each country specific investment constraints.

In order to compare observed returns against these four country specific benchmarks, this study uses all observed historical data as an attempt to evaluate the consistency of pension funds returns with the long-term objectives of the pension system. The appropriate time horizon for the evaluation of performance should be the life-time of different generations, including both the accumulation and withdrawal phases of the pension funds. However, given the relatively short history of privately managed mandatory pension funds, the exercise relies on an approximation of this, the period since the introduction of funded private pensions in each respective country. Unfortunately, for many countries, the private pension system started fairly recently and therefore it is impossible to maintain the ideal long term horizon when comparing pension funds investment performance. Additionally, for several countries there are no data from the start of the system, for certain domestic assets, such as corporate bonds, or government bonds.

In order to construct the benchmark portfolio, that is, a hypothetical combination of assets, which may not actually be invested, the exercise uses six asset classes: equities (national and overseas); government

\footnotetext{
${ }^{17}$ Ideally, one would like to select the portfolio that is highly correlated with wage growth. Unfortunately, it is quite difficult to come up with good data on wage growth across countries.
} 
bonds (national and overseas); money market securities (with overnight and 3 month maturities) and corporate bonds.

Investment performance is measured using the rate of return of the portfolio accumulated since the introduction of funded private pensions. The reason for choosing the accumulated rate of return is that, what matters to an investor in a pension fund is the accumulated return at the moment of retirement. The measure of risk used is the standard deviation of annual (monthly) returns over the period, which is a measure of the volatility of the returns.

Table 6 below presents the preliminary results of this benchmarking exercise for a few countries and only for two out of the four benchmarks. ${ }^{18}$ The annual mean return reported in column 3 corresponds to the actual return of the pension funds in each country. Annual mean returns reported in column 5 and 7 correspond to the benchmark portfolios $\mathrm{A}$ and $\mathrm{B}$, respectively. ${ }^{19}$ The results discussed are those of netting the returns of the benchmark portfolio from the returns of the actual portfolio (columns 9, 10 in Table 6). In this regards, a positive number means that countries' pension funds have done better than the benchmark portfolio.

The results indicates the performance of pension funds in most countries is below what it would have been possible, as indicated by the negative value of the returns net of benchmark returns for each country (column 9). Moreover, countries subject to quantitative investment restrictions have tended to underperform their benchmark portfolios (column 10) by a larger margin than the underperformance in the case that those restrictions would not have been in place (column 9).

Table 6. Countries pension funds' returns net of benchmark returns

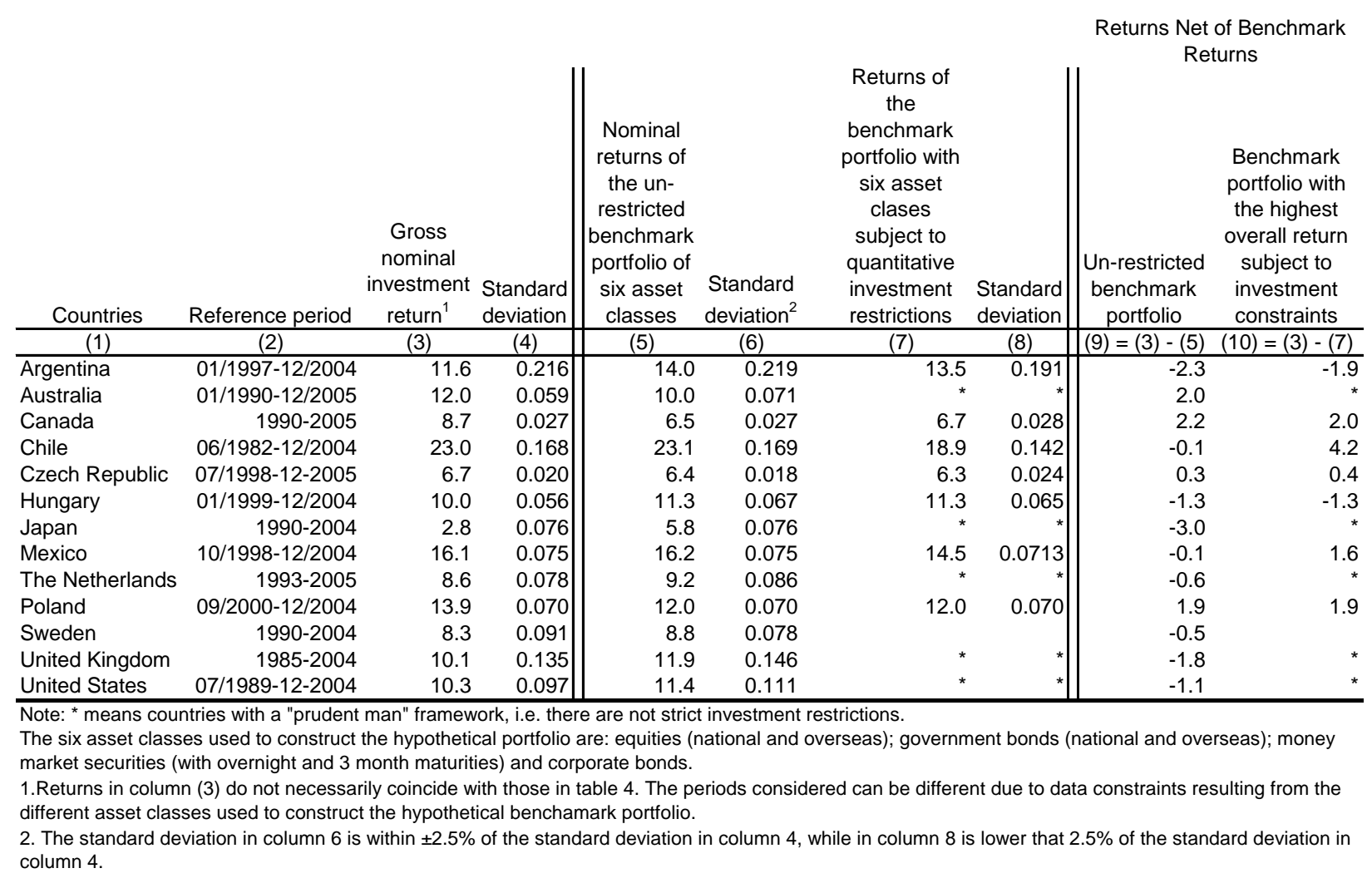

\footnotetext{
${ }^{18}$ Work is currently on-going to produce the results for benchmarks C and D.

${ }^{19}$ Column 4, 6 and 8 provide the standard deviations for reference.
} 
Strict limits in pension fund portfolio regulation may affect performance directly, by limiting the choice of assets portfolio managers have to choose from and therefore limiting the possibilities for performance enhancing portfolio diversification (for a given level of risk). In addition, they may affect performance in an indirectly way, as a result of the uncertainty over future changes in investment restrictions, which may affect the way managers make portfolio allocation decisions. It may change the investment horizon of the fund manager, from a long term (matching that of liabilities) to the current regulatory period, for which portfolio investment restrictions are known. Alternatively, if managers keep a long term investment horizon, uncertainty over future changes in investment restrictions may lead a "cautious" asset allocation that weights more heavily those assets which are less likely to be affected by future (unknown) changes in investment restrictions. This way of making asset allocation decisions may not necessarily be in the interest of fund members neither from the point of view of security nor from the point of view of performance.

\section{Some preliminary conclusions and further work.}

This paper has discussed the analysis carried out so far within the on-going OECD - World Bank project on comparing investment performance of privately managed pension funds across OECD, Latin American and CEE countries. The work has primarily focused first on collecting and analysing the available data to assess investment performance; and, secondly, on undertaking some preliminary evaluation of the performance of privately managed pension funds on a risk adjusted basis using Sharpe ratios and attribution analysis, and against some benchmark portfolios using ex-post Markowitz portfolio maximization. The main tentative conclusions from this work can be summarised as follows.

Firstly, the availability of adequate data has been an important limitation for conducting these studies, especially the evaluation of the risk-adjusted investment performance of pension funds. Section 3 provided some initial observations regarding the data that would be needed to undertake more in depth analysis of the risk-adjusted performance of pension funds. This could provide a starting point for an effort to develop international standards for the reporting of pension fund financial performance data that could support international comparisons and more in depth performance evaluation. A more structural problem is the fact that most of the private systems have less than 10 years of history, which imposes a restriction for examining the long-term nature of investment performance.

Secondly, Sharpe ratio and attribution analysis show that, for those countries with enough information and data to adjust returns accordingly, privately managed pension funds have obtained a risk premium against short-term investment alternatives.

Thirdly, pension funds have generally underperformed with respect to the hypothetical portfolio with the highest (mean) return for a given level of risk (i.e. an ex-post efficient frontier). Interestingly, the analysis suggests that in several countries investment restrictions have had a negative impact on performance.

As noted above, this initial effort is limited by both the available data and the applicability of performance measurement methodologies developed for more general analysis (i.e., the Sharpe Ratio) to the nature of pension funds. In particular, the time frame of pension funds is long-term in nature, while most of the measures used to assess their performance are of short-term nature, which may not necessarily being optimal from a long-tem perspective. Consequently, the next stage of the work would focus on developing system and country specific benchmarks against which pension funds should evaluate their long-term performance; benchmarks that would allow assessing the impact of pension design and different regulatory environments on the investment performance of privately managed pension funds across the world. Similarly, future wok will focus on establishing a common framework for the reporting of data and performance results. 
The current on-going work includes (1) the development of a model to use as a framework for the design of benchmarks for pension funds, taking into account their long-term nature; (2) applying those benchmarks to evaluate investment performance in those countries were relevant data is available, and assessing the impact of the characteristics of each pension system in general (distinguishing between mandatory and voluntary systems, and DB and DC arrangements), and their regulatory environment in particular; (3) projections of pension income and wealth for selected pension systems; (4) an analysis of life cycle investing by pension funds; and (5) an analysis of the implications of return guarantees.

\section{REFERENCES}

Michaud, R. (1998), Efficient Asset Management, Harvard Business School Press, Boston, Massachusetts.

Sharpe, W. (1966), “Mutual fund performance.” Journal of Business 39(1), 119-138.

Sharpe, W. (1992), “Asset allocation: management and performance measurement.” Journal of Portfolio Management, Winter pp. 7-19.

Tapia, W. (2008a), "Private pension systems across countries", OECD Working Paper on Insurance and Private Pensions, No. 21.

Tapia, W. (2008b), “Comparing aggregate investment returns in privately managed pension funds", OECD Working Paper on Insurance and Private Pensions, No. 22.

Walker, E. (2006), "Cobertura cambiaria e inversión internacional de portafolio: Una perspectiva local". Economía Chilena, Vol. 9 (2), p. 41-59, Banco Central de Chile.

Walker, E. (2007), "Strategic Currency Hedging and Global Portfolio Investments Upside Down" forthcoming in the Journal of Business Research, Elsevier.

Walker, E., and A. Iglesias (2007), "Financial Performance of Pension Fund Systems around the World: An Explanatory Study", report prepared for the OECD - World Bank project on Investment Performance of Privately Managed Pension Funds. 